ORIGINAL

PROF-1094

\title{
LOW SERUM CALCIUM ASSOCIATED WITH TUBERCULOSIS
}

\author{
DR. M AKHTER BAIG \\ Associate Professor, \\ Department of Orthopedic Unit I, \\ Dow University of Health Sciences Karachi. \\ DR. LUTUFULLAH BALOCH, \\ Assistant Professor, \\ Department of Orthopedic Unit I, \\ Dow University of Health Sciences Karachi.
}

\section{DR. GHULAM MUSTUFA KAIAM KHANI \\ Assistant Professor, Department of Orthopedic Unit I, Dow University of Health Sciences Karachi.}

\author{
Dr. Mushtaque Ahmed Qureshi, \\ Professor and Head of Department of Orthopedic \\ Dow University of Health Sciences Karachi.
}

\begin{abstract}
Design: A prospective study. Place and Duration of study: Department of Orthopedic at Liaquat medical college from January 1997 to June 2001 and continued at Dow medical college from Oct 2001 to march 2005. Patients and Methods: 33 patients suffering from tuberculosis out of them 22 was female and 11 were male. In this study we are able to pin point the exact nutritional factor responsible for the development of tuberculosis. Results: We are able to find that in our all-33 tuberculous patients serum calcium was low. Conclusion: We conclude that low serum calcium have definite roll in the development of tuberculosis. Calcium supplements along with Vitamin D should be added for the treatment and prevention of the disease.
\end{abstract}

Key words: Serum Calcium, Tuberculosis.

\section{INTRODUCTION}

Tuberculosis is probably oldest disease known to mankind ${ }^{1}$. It is commonly seen in the poor population of developing countries including Pakistan. However, it is still, the growing danger of developed countries among old age group and patients with AIDS ${ }^{2}$. The disease is caused by Mycobacterium tuberculosis. Among predisposing factors poor nutrition, underprivileged living conditions, dark home, offensive hygiene and the low immunity are blamed, along with history of close association with patient of tuberculosis. Which of the nutritional factor exactly responsible for the nourishment of Mycobacterium tuberculosis in human body still to be recognized? In this present study we able to recognize the exact nutritional factor. That is low serum calcium. Patient with low serum calcium always going to develop tuberculosis provided he or she is living in close contact of other tuberculous patients. The idea flown in my mind during conducting the OPD of patients with tuberculosis of bone and joints always complaining of whole body aches. Forced us to do serum calcium of these patients. When the serum calcium of these patients were 
determined. It was surprising for us, that almost all patients with tuberculosis not having additional calcium or vitamin D supplement or not on steroid therapy were having low serum calcium. This accidental finding strained us to collect the data of all our tuberculous patients and shared our sighting to entire medical community. This is amazing that local literature absolutely unvoiced except the free paper of author ${ }^{3}$ him selves about this finding. However our contemporary abroad has already worked on this subject and our finding are matching with their succeed ${ }^{4,5}$.

\section{MATERIAL AND METHODS}

The Study was conducted on adult patients in the Department of Orthopedic surgery unit I at civil Hospital Hyderabad during my posting at Hyderabad from Jan 97 to June 2001 and continued in Civil Hospital Karachi in the department of orthopedic unit I after my arrival at DMC in Oct 2001. Few patients from my private clinic were also included in the study. The study was started in 1997 and continued up to March 2005. The study was based upon the laboratory results of serum calcium of proved tuberculous patients. Patients were labeled tuberculous if they are sputum positive, or their biopsy shows typical tuberculous granuloma or on typical x-ray findings (e.g. T.B spine in which loss of disc space is the typical finding.) and other substantial clinical evidence of tuberculosis including response to antituberculous drugs. All selected patients with proved tuberculosis were evaluated for history, examination hematological tests and radiological assessment.

The Patients were followed for six months to two years both clinically and radio logically. Complication and out come recorded. All data were recorded on a prescribe form, prepared carefully. All selected patients with proved tuberculosis were evaluated for history, examination hematological tests and radiological assessment. All tuberculous patients on steroid therapy or patients who are taking additional calcium and vitamin D supplements in last three months are excluded from our study. Similarly tuberculous patients with diseases known to cause hypercalcaemia e.g. hyperparathyroidism and certain renal diseases were also excluded from our study.

\section{RESULTS}

Total No of patients were 33 with 11 male and 22 female with male female ratio exactly 1:2. Most of the cases were reported in their reproductive age as shown in table.

\begin{tabular}{|l|c|c|c|}
\hline \multicolumn{4}{|c|}{ Table-I. Age incidence. } \\
\hline Age group & Male & Female & Total \\
\hline 0-10 years & 1 & 2 & 3 \\
\hline 11-20 years & 3 & 11 & 14 \\
\hline 21-30 years & 5 & 3 & 8 \\
\hline 31-40 years & 1 & 2 & 3 \\
\hline $41-50$ years & 1 & 2 & 3 \\
\hline Over 50 years & 0 & 2 & 2 \\
\hline Grand total & 11 & 22 & 33 \\
\hline
\end{tabular}

Social and economical condition and residential area of all patients was poor. Almost $54.54 \%$ of patient was living in semi dark home however about $21.21 \%$ of patients having negligible sun light exposure and $68.69 \%$ were having partial exposure to sun light.

Around $54.54 \%$ of patients the diagnosis was on biopsy. $9.09 \%$ of patients were having sputum positive. $36.36 \%$ patients were on typical X-ray finding as seen TB spine, however history, examination, laboratory findings and clinical response to anti-tuberculous drugs were all taken in to account before labeling them tuberculous. Majority of our cases belong to spine (60.60\%). $9.09 \%$ cases from pulmonary tuberculosis. Remaining $30.30 \%$ from other part of musculoskeletal system, like left scapulae, wrist, knee, right and left hip, ankle joint, left ulnar head, trochantric bursa, proximal phalanx of 2 nd toe. (One case from each side). Among spine, lumber spine is the most common site to involve where as dorsal spine cervical spine and sacral region is to follow the order. 


\begin{tabular}{|l|c|c|c|}
\hline \multicolumn{3}{|c|}{ Table-II. Spinal involvement. } \\
\hline Site in the spine & Male & Female & Total \\
\hline Cervical spine & 0 & 2 & 2 \\
\hline Dorsal spine & 1 & 5 & 6 \\
\hline Lumber spine & 1 & 10 & 11 \\
\hline $\begin{array}{l}\text { Sacral region and Lt. Inguinal } \\
\text { lymph node }\end{array}$ & 0 & 1 & 1 \\
\hline Grand total & 2 & 18 & 20 \\
\hline
\end{tabular}

$54.54 \%$ were newly diagnosed cases of tuberculosis out of them $39.39 \%$ were female. $45.45 \%$ were already diagnosed and were on anti-tuberculous therapy. Among these old $45.45 \%$ cases $30.30 \%$ also female. All old cases were on ATT from several months to 2 years. However none of them old or fresh case were not taking vitamin $\mathrm{D}$ and calcium supplemented in their diet, except one male of 18 years of age, who is taking one glass of milk off and on with out proper exposure to sunlight or taking vitamin D supplement. His Ca. level was found relatively better but still low that is $8.4 \mathrm{mg} \%$. Calcium level was below normal in all case. Our normal limit was $8.8 \mathrm{mg} \%$ in our series its value varies from 5.0 to 8.4 . It is surprising that two of our patients were having serum calcium as low as 5.0 however none of patients in our series complained of tetany.

Serum phosphorus was raised in $42.42 \%$ lowered $3.03 \%$ and remains normal in $54.54 \%$, out of them $24.24 \%$ male and $30.30 \%$ were female. Alkaline phosphatsease was raised in $63.63 \%$ (42.42\% female and $21.21 \%$ male) it was remain normal in $36.36 \%$ of patients. (24.24\% female and $12.12 \%$ male)

\section{DISCUSSION}

Tuberculosis is the disease of people who lived in under privilege condition like dark home and poor nutritional intake especially milk. It is a well-known fact that poor exposure to sunlight results in Vitamin D deficiency that along with low intake of milk leading to hypocalcaemia. Low serum calcium does not considered the predisposing cause of tuberculosis until the recent past, where different workers from different centers of the world are able show that tuberculous patients are often associated with hypocalcaemia ${ }^{3,4,5}$. Low serum calcium in these patients also associated with vitamin- D deficiency ${ }^{6,7,8}$. This Vitamin $D$ deficiency in patients with tuberculosis is possibly a cause rather than effect of the disease; deficiency is due to decreased dietary intake. Vitamin $D$ deficiency can occur without any symptoms. If symptoms are present, it indicates severe deficiency. Serum calcium and phosphorus values do not often predict the existence of deficiency ${ }^{8,9}$. We agree with our contemporary fellows however in our series in all tuberculous patients on steroid therapy or patients, which are taking additional vitamin D, supplements in last three months are excluded from our study. Similarly tuberculous patients with diseases known to cause hypercalcaemia e.g. hyperparathyroidism and certain renal diseases were also excluded. These strict excluding criteria might be the true reflection of disease that all tuberculous patients having hypocalcaemia irrespective site sex and extent of lesion in our series.

Calcium and vitamin $D$ has an important role in the control of tuberculous infection. The ability to kill mycobacterium tuberculosis by macrophages and monocytes is reduced in the absence or in the deficiency of extra cellular and intra-extra cellular calcium ${ }^{10,11}$. Similarly Vitamin D deficiency is associated with an increased risk for tuberculosis infection. Studies using in vitro systems indicate that 1,25-dihydroxyvitamin D (3) [i.e. $1,25(\mathrm{OH})(2) \mathrm{D}(3)]$, the most active form of the vitamin, enhances mycobacterium killing by increasing nitric oxide (NO) production, a potent anti-microbial mechanism of activated macrophages, and suggest that $1,25(\mathrm{OH}) 2 \mathrm{D} 3$ also limits host damage ${ }^{6,7}$.

Clinically it is also observed patient with proved tuberculosis does not respond to antituberculous therapy until vitamin $D$ is added ${ }^{9}$. We differ in this respect that calcium supplement must be add along with vitamin $D$ to get excellent clinical response to antituberculous therapy, as this is been continuously observed in our series as well. 


\section{CONCLUSIONS}

We conclude that low serum calcium have definite role in the development of tuberculosis. The current literature also supported our finding furthermore; it says that vitamin $D$ has a direct role in killing of mycobacterium tuberculosis apart through elevation of serum calcium. Therefore we advocate Calcium supplements along with Vitamin $D$ should be added for the treatment and prevention of the disease.

\section{REFERENCES}

1. Le Vay David. The History of Orthopedic. The Parthenon publishing group. 1990 4-5.

2. Jellis John E. Heamatogenous osteomyelitis. Journal of Pakistan Orthopedic Association. 1997: vol 9 (supplement) 61-64.

3. Baig M Akhter. Low serum calcium associated with tuberculosis 2nd OASAC, SICOT, ASAMI and 16th ORTHOCON Karachi PAKISTAN. $20025^{\text {th }}-8^{\text {th }}$ April.

4. Ali-Gombe A, Onadeko BO. Serum calcium levels in patients with active pulmonary tuberculosis. Afr J Med Med Sci. 1997 Mar-Jun;26(1-2):67-8.

5. Kalita J, Misra UK, Ranjan P.Tuberculous meningitis with pulmonary miliary tuberculosis: a clinicoradiological study. Neurol India. 2004 Jun;52(2):194-6.
6. W. R. Waters $, 1,{ }^{*}$ B. J. Nonnecke,2 T. E. Rahner,1 M. V Palmer,1 D. L. Whipple,1 and R. L. Horst2 Modulation of Mycobacterium bovis-Specific Responses of Bovine Peripheral Blood Mononuclear Cells by 1,25Dihydroxyvitamin D3 Tuberculosis (Edinb). 2003;83(5):287-97.

7. WR Waters, MV Palmer, BJ Nonnecke, DL Whipple, RL Horst Mycobacterium bovis infection of vitamin Ddeficient NOS2-/- mice Microb Pathog. 2004 Jan;36(1):11-7.

8. Sasidharan PK, Rajeev E, Vijayakumari V. Tuberculosis and vitamin $\mathbf{D}$ deficiency. J Assoc Physicians India. 2002 Apr;50:554-8.

9. Sasidharan P.K. Tuberculous Osteomyelitis and Vitamin D deficiency. J.Orthopaedics 2004;1(2)e3.

10. Majeed M, Perskvist N, Ernst JD, Orselius K, Stendahl O. Roles of calcium and annexins in phagocytosis and elimination of an attenuated strain of Mycobacterium tuberculosis in human neutrophils. : Microb Pathog. 1998 May;24(5):309-20.

11. Carmel B. Stober, David A. Lammas, Cheuk M. Li, Dinikantha S. Kumararatne, Stafford L. Lightman and Craig A. McArdle ATP-Mediated Killing of Mycobacterium bovis Bacille Calmette-Guérin Within Human Macrophages Is Calcium Dependent and Associated with the Acidification of Mycobacteria-Containing Phagosomes. The Journal of Immunology, 2001, 166: 6276-6286. 